\title{
Effects of word- and sentence-level contexts upon word recognition
}

\author{
LUCIA COLOMBO and JOHN WILLIAMS \\ University of Padua, Padua, Italy
}

\begin{abstract}
In the present experiments, we investigated the facilitatory effects of auditorily presented prime words in neutral sentence contexts upon visually presented target words. It is shown that when the target task is a lexical decision, facilitation is obtained when the relationship between the prime and the target is one of synonymy (and low association strength). When instead the target is an antonym (again of low association strength), there is no priming effect; lexical decision is facilitated only when the prime word is presented in isolation. In further experiments, it is shown that primes in sentence contexts can produce facilitation of antonyms if they are strongly associated, or in the absence of association if the target must be named. The results are explained in terms of an integration process, which checks for the coherence between an upcoming word and the highest available level of representation of the context, but which affects only responses in the lexical decision task.
\end{abstract}

The priming effect has been extensively studied, especially in single-word paradigms (Meyer \& Schvanenveldt, 1971; Neely, 1976, 1977), and the theoretical concepts underlying it have been part of the main models of lexical access (Becker \& Killion, 1977; Forster, 1976; Morton, 1969).

Studies on priming have often considered the problem of how the strength of the relation between the prime and the target influences performance on the task (Lorch, 1982; Warren, 1974). However, very few studies have considered whether the type of semantic relation between the prime and the target influences performance. For instance, Williams (1988) found that a prime word included in a sentence context did not facilitate recognition of the subsequently presented target word when the prime and the target were connected by a pragmatic relation, such as "table-chair." Williams's results suggest that the type of priming relation may be an important feature of the priming process itself.

In Experiment 1, two types of semantic relations between prime and target were investigated-namely, synonyms and antonyms. Synonyms (e.g., "sure-certain") are linguistically defined as having the same meaningthat is, as being substitutable in an expression without changing its descriptive meaning (Lyons, 1977). Synonyms share identical sets of semantic components (Clark \& Clark, 1977). Synonyms also are semantically close

\footnotetext{
The present work is based on a paper presented at the 28th Meeting of the Psychonomic Society held in Seattle, November 1987. The research was supported by a grant to the first author from Fondi $60 \% 1987$. The second author was supported by a Research Fellowship from the Royal Society of Great Britain, and is now at the Centre of English as an International Language, Cambridge, U.K. The authors wish to thank Sandro Bettella for writing the programs for the experiments and for his helpful assistance in setting up the laboratory. Requests for reprints may be sent to Lucia Colombo, Dipartimento di Psicologia Generale, Piazza Capitaniato 3, 35139 Padua, Italy.
}

to antonyms, although antonyms reflect a relation of contrast (e.g., "sure-unsure"), based on only one component. In a pragmatic relation, two words may not share any semantic component (e.g., "pram-baby") and may be connected only because of the relation that the objects they denote have in the world. They could therefore be conceived as being embedded in schematic representations such as "scenarios" (Sanford \& Garrod, 1981). According to the spreading-activation theory, one should expect that access of a target word is facilitated more by semantically close primes (synonyms and antonyms) than by semantically distant primes, because the former share more nodes in the semantic network.

It is possible, however, that compared to synonyms, antonyms' feature of opposition, or contrast, might reduce their priming ability. Let us suppose that preactivation of related words depends on the quality, as well as on the number, of shared features. The feature of contrast that antonyms share might therefore have the consequence of weakening a priming effect. In most priming studies, several types of semantic relations are mixed together, so it is not possible to identify the contribution of each to the total facilitation effect. Becker (1980) found a priming effect for antonyms, but the words were strongly associated and were presented in isolation. The synonyms and antonyms studied in Experiment 1 were very low in association strength, so that the priming effect obtained reflected the semantic relation existing between the two words, not other factors such as, for instance, frequent co-occurrence in the language. Moreover, to test the priming effect in as natural a context as possible, the prime word was embedded in an auditorily presented neutral sentence context (e.g., "In order to be kept dry ...") and was followed immediately at its offset by a target word that could be either a synonym ("arid") or an antonym ("damp"). The subjects were required to make lexical 
decisions about the target words. If the presence of a feature of opposition has an effect, then less facilitation should be expected for antonyms than for synonyms, with respect to a control condition.

\section{EXPERIMENT 1}

\section{Method}

Subjects. A total of 32 subjects took part in the experiment. The subjects in this and in the subsequent experiments were students from the University of Padua, mainly female, who volunteered as unpaid subjects. No subject participated in more than one experiment presented in this paper.

Material. The prime and target pairs were constructed in the following way. For each prime word (e.g., SECCO) to be included in a sentence context, a synonym and an antonym (e.g., ARIDO and UMIDO) were chosen as target words. The semantically related pairs of synonyms and antonyms (e.g., SECCO-ARIDO and SECCO-UMIDO) were selected in such a way as to be either very low associates or not associated at all. Eighteen triples were selected in this way, according to the judgment of the experimenters. The association strength of the pairs of words was checked in Parisi and Pizzamiglio's (1967) norms, although not all the words were included in the norms. The mean frequency of the synonym targets selected was checked in the "Lessico di frequenza della lingua italiana" (Bortolini, Tagliavini, \& Zampolli, 1982) and was found to be 41 (on a count of 500,000 ). When one exceptionally frequent item ("certo," 402) was excluded, the mean frequency dropped to 20 . The mean frequency of the antonyms was comparable (27). Mean length in letters was 5.5 and 5.7 for synonyms and antonyms, respectively. Eighteen more words were added, to be used as control primes. They were unrelated to both the synonym and the antonym targets, according to the intuitions of the authors, and were as similar as possible to the prime word in length. Thus, a total of 36 prime words and 36 target words were used as critical items. In addition to the critical target words, 10 more words and 24 nonwords were selected to be used as targets for the filler sentences. The nonwords were pronounceable but were not similar to any of the test or filler words.

For each of the 18 critical prime words, a sentence frame was constructed, to be used as context. The sentences were constructed in such a way as to be neutral with respect to the prime word, and not to contain any related word that either preceded or immediately followed it (e.g., "In order to be kept dry ...") (see Appendix). The same 18 sentences, identical except for the word to be used as the prime, were used in the control condition. There were therefore two lists of 18 experimental sentences each for the synonyms group. Each list contained all the items in either the related or the control condition. The sentences that contained prime words that were synonyms of the target in the first list contained the control prime in the second list, and vice versa. The same was the case for antonyms in the third and fourth lists. In addition to the critical sentences, each list included 34 filler sentences and six additional sentences to be used as practice at the beginning of the list. Each subject heard a total of 58 sentences. Eight subjects were tested on each of the four possible lists.

Procedure. The sentences were recorded with a Revox tape recorder by a male speaker who read them at a normal reading rate, with an interval of about $5 \mathrm{sec}$ between each sentence. Coincident with the offset of each experimental word, which was found by turning the tape by hand, a pulse was set by means of a remote-control switch (Diapilot). This pulse caused the immediate appearance of the target word for $1,200 \mathrm{msec}$ on the monitor display of an Apple Ile microcomputer attached to the tape recorder. Pulses were also placed at the offset of one of the words in each filler sentence. Since for the critical items the target occurred quite early in the sentence, for the 10 fillers with word targets, the timing pulse was placed after a word toward the end of the sentence. For the nonword fillers, the targets were spread evenly over all possible positions.

The subjects were seated in front of the microcomputer, with their right and left index fingers resting on the " 9 " and " 5 " keys of the keyboard, respectively. They listened to the sentences in the earphones and watched the monitor; when a letter string appeared, they had to decide as soon as possible whether it was a word or not, by pressing the 9 or the $5 \mathrm{key}$, respectively. They were instructed to listen to the sentences with attention, their task being to understand the sentences, not to memorize them word for word. Moreover, they were instructed to look at the screen, where a letter string could appear, in order to be ready to respond as quickly as possible and before it disappeared spontaneously after $1,200 \mathrm{msec}$. The subjects were also told that at the end of the experiment they would be given a recognition test on the sentences just presented. The recognition test was used only to make sure that the subjects had paid attention to the sentences, and no record was taken of it. Reaction times were automatically recorded from the onset of the target words on the screen until the subject pressed a key.

\section{Results}

In this and all subsequent experiments, reaction times that exceeded $1,200 \mathrm{msec}$ were automatically removed by the computer $(1.38 \%)$ and values $2 S D$ above or below the subjects' mean reaction times were not included in the analysis ( $2.4 \%$ of the data was removed in this way). ${ }^{1}$ In addition, $0.3 \%$ of the data was lost due to mechanical errors. An analysis of variance (ANOVA) was carried out on the mean reaction times of correct responses, with one between-groups factor (synonyms vs. antonyms) and one within-groups factor (related vs. control). The results showed that, although on the whole the difference between primed and unprimed targets was significant by subjects $[F(1,30)=4.04, p<.01]$, and marginally significant by items $[F(1,34)=2.7, p>.10]$, this facilitation effect was entirely due to the synonymic pairs, as shown by the mean reaction times in Table 1 . The interaction was significant by subjects $[F(1,30)=7.39, p<.05]$, but not by items $[F(1.34)=1.49, p>.10]$. The betweengroups factor of synonyms versus antonyms was also significant, both by subjects $[F(1,30)=4.7, p<.05]$ and by items $[F(1,34)=10.6, p<.01]$.

Separate analyses on the data for synonym and antonym pairs showed a facilitation effect for synonyms, which was significant by subjects $[F(1,15)=10.7, p<.01]$, but

Table 1

Mean Lexical Decision Times (in msec) and Percentage of Errors for Synonym and Antonym Targets in Sentences (Experiments 1 and 3)

\begin{tabular}{|c|c|c|c|c|}
\hline \multirow[b]{2}{*}{$\begin{array}{c}\text { Type } \\
\text { of Target }\end{array}$} & \multicolumn{2}{|c|}{ Related Pairs } & \multicolumn{2}{|c|}{ Unrelated Pairs } \\
\hline & $\begin{array}{c}\text { Decision } \\
\text { Time }\end{array}$ & $\begin{array}{c}\% \\
\text { Errors }\end{array}$ & $\begin{array}{c}\text { Decision } \\
\text { Time }\end{array}$ & $\begin{array}{c}\% \\
\text { Errors }\end{array}$ \\
\hline \multicolumn{5}{|c|}{ Experiment 1} \\
\hline Synonyms & 716 & 2.0 & 752 & 7.6 \\
\hline Antonyms & 666 & 1.4 & 661 & 5.5 \\
\hline \multicolumn{5}{|c|}{ Experiment 3} \\
\hline Associated & & & & \\
\hline Antonyms & 615 & 1.4 & 653 & 2.1 \\
\hline
\end{tabular}


only marginally significant by items $[F(1,17)=3.24$, $p>.05]$. No priming effect was found for antonyms [subjects, $F(1,15)=0.26$; items, $F(1,17)=0.13$ ]. Lexical decision, then, was faster when the target word was a synonym of the prime, but not when the target was an antonym, relative to the control. It should be noted that neither the facilitation effect for synonyms nor its interaction with antonyms was significant in the analysis by items. This may be due, in part, to the fact that fewer (eight) observations contribute to each cell mean on the item analysis than on the analysis by subjects (nine).

An ANOVA was also conducted on the means of the errors. The proportion of errors was $2 \%$ in the related condition and $7.6 \%$ in the unrelated condition for the synonyms, a marginally significant difference by subjects $[F(1,15)=4.3, p>.05]$ and by items $[F(1,17)=3.7$, $p>.10]$. For the antonyms, the mean proportions of errors were significantly less in the related than in the unrelated condition $[1.38 \%$ and $5.5 \%$, respectively; subjects, $F(1,15)=5.9, p<.05$; items, $F(1,17)=3.4, p>.10$ ]

To check whether the lack of a facilitation effect on reaction time for antonyms could possibly be due to a difference in association strength with respect to synonyms, a test of association was conducted in the following way. An independent group of 43 psychology students were given a booklet containing the critical prime words of Experiment 1. They were asked to write, after reading each word, the first word that came to mind. The results showed that relatively fewer of the synonym and antonym targets were given as associates of the primes: the synonym and antonym targets were produced as associates by $9 \%$ and $6.2 \%$ of the subjects, respectively. One synonym pair was found to be highly associated ("breve-corto," $51 \%$ ). When this pair was excluded from the count, the mean association strength was $6.6 \%$ and $5.9 \%$, respectively. Further analyses were conducted on the data after removing this item, but the pattern of results remained unchanged. The interaction between groups (synonyms vs. antonyms) and type of prime (related vs. unrelated) was again significant by subjects $[F(1,30)=6.4$, $p<.05]$, but not by items $[F(1,32)=1.22, p>.1]$. The ANOVA on the means for the synonym condition was significant by subjects $[F(1,15)=10.3, p<.01]$, but not by items $[F(1,16)=2.5, p>.1]$, whereas that for the antonym condition did not even approach significance [subjects, $F(1,15)=.08$; items, $F(1,16)=.07$ ]

\section{Discussion}

The results of the first experiment show that a prime word embedded in a neutral context speeds lexical decision on the target word only when it is a synonym. No priming effect is apparent when the target is an antonym. This result is rather surprising, given that antonyms are highly related in meaning. Does this mean that activation did not "spread" to antonymous targets? The error data suggest that in fact this was not the case, since significantly fewer errors were made in the related condition than in the unrelated condition. Hence, it could be argued that preacti- vation of the antonym targets was occurring, but for some reason this was not apparent in the reaction times.

Given that Becker (1980) found a facilitating effect for highly associated antonyms presented in isolation, the lack of a priming effect on response times in the current experiment might be due either to the processing demands required by the presence of a sentence, or to the fact that the words were only semantically related, not associated. In Experiments 2 and 3, we consider these two possibilities.

One reason for the lack of a reaction-time facilitation might lie in the way the prime word is processed. It could be that when the prime word is embedded in a sentence, the facilitation effect is obscured by other factors and appears only when the response is for some reason either anticipated or given when processing is incomplete, producing an error. This possibility is bolstered by Smith's (1979) finding that the presence of a facilitation effect depended on how the prime word was processed. In that study, when the task required a letter search of the prime, no reaction-time advantage was found for semantically associated pairs, although there was priming in errors. Similarly, Hoffman and Macmillan (1985) found a dissociation between reaction times and errors in an experiment in which subjects did not focus their attention on the prime word, because the main task was a letter search on another word that was some distance away from it.

A number of other studies have also failed to obtain priming between semantically related words when the prime occurs in a sentence context. Auble and Franks (1983) found that recognition of a masked target word was not facilitated when it was preceded by an associated word if it was not related to the sentence context containing the prime. Williams (1988) found the same result using both lexical decision and naming of degraded targets. Foss and Ross (1983) found a similar effect for related word pairs embedded in sentence contexts, this time using a phoneme-monitoring task.

Experiment 2 was devised to determine whether the antonym pairs used in Experiment 1 could produce priming of reaction times when presented in isolation.

\section{EXPERIMENT 2}

\section{Method}

Subjects. Sixteen subjects took part in this experiment.

Material. The 18 antonym pairs of Experiment 1 served as critical prime-target pairs in Experiment 2. Two lists were formed. Each list included half of the experimental primes in the related condition and half in the neutral condition. There were 18 criticalword targets, nine filler words, 25 nonwords, and four words and two nonwords used as practice at the beginning, for a total of 58 items. The subjects were randomly assigned to one of two groups; each group received one list.

Procedure. The same male speaker read the prime words for Experiment 2 . The words were read at a normal rate, with an interitem interval of about $3 \mathrm{sec}$. A timing pulse was placed at the offset of each word, which initiated presentation of the target string on the monitor. The subjects were told to pay attention to the auditorily presented words, that there would be a recognition test at 
the end of the experiment, and to make lexical decisions on the visually presented words as quickly and as accurately as possible. As with Experiment 1, no record was taken of the recognition test.

\section{Results and Discussion}

The analysis of the results was based on the mean reaction times of the correct responses, excluding four responses $(1.3 \%)$ that exceeded $1,200 \mathrm{msec}$ and $2 \%$ of the data that exceeded $2 S D$. Mean lexical decision times were $595 \mathrm{msec}$ for related targets and $641 \mathrm{msec}$ for unrelated targets [subjects, $F(1,15)=9, p<.01$; items, $F(1,17)=$ $12.2, p<.01 ; \min F(1,31)=5.17, p<.05]$. The proportion of errors was very low in both conditions ( $2 \%$ and $4.1 \%$, respectively, for related and unrelated targets), and in the same direction as the reaction times.

The results of Experiment 2 indicate that the semantic relation existing between the members of the antonym pairs used in Experiment 1 was sufficiently strong to produce priming, at least when they were presented in isolation. So why did this effect disappear when the primes occurred in a sentence (Experiment 1)? One possibility is to consider what constitutes the "effective context" in the two situations (Foss \& Ross, 1983). When the prime word is isolated, attention is focused directly on it, and its relationship with the target becomes straightforward. But when the prime is included in a sentence context, and the primary task of the subject is to understand the sentence, then by the time the target appears, the prime word may be integrated into the sentence. The effective context for a lexical decision on the target word could be the whole sentence, not just the prime word.

Now it is reasonable to assume that a word is coherent with a context containing a synonym, because that word corroborates what has just been asserted by the sentence context (e.g. , compare "In order to be kept dry-ARID," and "In order to be kept clear-ARID"). Even though the word does not form part of the sentence, and does not require "integration" into that sentence in the normal sense, we can nevertheless reasonably assume that the information carried by the target interacts in some way with the information brought about by the sentence, and can extend the notion of integration to a more general "fit" with the message-level content of the utterance (Forster, 1981; Norris, 1986). If we assume with Forster that the coherence between a word and a sentence context is most readily detected at the message level, then this will endow the word with the meaningfulness required to make a positive lexical decision response. Consider instead the case of an antonym (e.g., "In order to be kept dryHUMID" vs. "In order to be kept clear-HUMID"). In this case, the target tends to negate what has just been asserted in the sentence, and in this sense it does not "fit." Therefore, the message level provides no ready clues as to the meaningfulness of the stimulus, and the relation of opposition is likely to create a conflicting situation. In this view, lexical decision responses are not sensitive to the ease of recognition of the target words as such, but rather to the fit between the meaning of the target word and that of the sentence context, a process that occurs at a postrecognition level of processing.

According to the above explanation, it is possible that there were two processes going on in Experiment 1, each contributing in a different way to the final outcome. The first would be the priming of recognition of both synonym and antonym targets by spreading activation around the conceptual network. This would produce preactivation of nodes at the lexical level. The second is a process influenced by the presence of a sentence context, which could be either integration at the message level or a checking of coherence between the lexical output and the message level (Forster, 1981). This second type of process would have the consequence of slowing down lexical decisions on targets that are incongruent, as is the case with antonyms. If lexical decision errors reflect a premature response based upon incomplete processing, then they are more likely to show the influence of the first "recognition" stage than the second "postrecognition" stage. This would explain why, in Experiment 1, we found priming in errors but not in reaction times. Admittedly, reliance on an explanation based on equal and opposite effects is weak, and is very difficult to verify. However, there may be a way to enhance one of the two factors, thereby assisting an indirect discrimination between them.

One might try to enhance the effect of the lexically based process by incrementing the strength of the prime-target relationship. It has been suggested that strong associates produce a greater facilitation than do weaker associates (Neely, 1977; Warren, 1974). In Experiment 3, strongly associated antonyms, such as bipolar opposites ("hotcold'), were presented following a neutral context. If the presence of a strong link between the prime and the target produces a larger facilitation, this might "compensate" the conflicting mechanism that tends to slow down responses. Therefore, a priming effect might also appear in the reaction times of responses to antonym targets.

\section{EXPERIMENT 3}

\section{Method}

Subjects. Twenty subjects volunteered in this experiment.

Material. Fourteen pairs of associated antonyms were selected from the Italian association norms (Parisi \& Pizzamiglio, 1967). The mean association strength was $45 \%$. Fourteen sentences were also constructed, to be used as sentence contexts for the prime words. The prime word was the first member of the associated pair. The part of the sentence preceding the prime was composed in such a way as to be neutral with respect to the prime (see Appendix). For each experimental sentence, a second version was written in which the prime word was substituted by a control word of similar length. A total of 27 of the filler sentences used in Experiment 1, plus the six practice sentences, were used as fillers in the present experiment. Two lists were formed such that each list contained half of the sentences with critical primes and half of the sentences with control primes. Target words were formed by the second member of each associated pair, plus eight filler words and 19 nonwords.

Procedure. The apparatus and procedure were the same as in Experiment 1 


\section{Results and Discussion}

Two data points $(0.7 \%)$ were excluded in this experiment because of mechanical problems, one datum point $(0.2 \%)$ was cut off because it fell more than $2 S D$ above the subject mean. Mean reaction times of lexical decision on targets associatively related to the prime word were faster than on unrelated targets [subjects, $F(1,19)=6.6$, $p<.05$; items, $F(1,13)=4.1, p>.05$ ] (see Table 1). The proportion of errors was very low: $1.42 \%$ for the related condition and $2.14 \%$ for the unrelated condition. Thus, according to these data, strongly associated antonym pairs can produce a priming effect even in a sentence context, although the effect is rather weak and is only significant in the subjects' analysis (it should be noted, however, that the item analysis was less powerful than the subjects' analysis, since there were only 14 items, as opposed to a total of 20 subjects). This result is consistent with the view that, in contrast to Experiment 1, a large amount of priming of target recognition was sufficient to overcome any opposing effects at the postrecognition stage.

It has recently been claimed (Balota \& Lorch, 1986; Forster, 1981; Lupker, 1984; Seidenberg, Waters, Sanders, \& Langer, 1984) that the decision mechanism involved in the lexical decision task is probably sensitive to contextual factors, so that at least some of the priming effect usually found with the lexical decision task is due to operations occurring after lexical access of the target word. Consequently, when a semantic relation between a prime and a target is detected, the response to the target is speeded, more than it is when the target must simply be named. If this claim is correct, then the use of another paradigm that does not involve postaccess mechanisms should allow the priming effect due to the semantic relation of the prime and the target to appear. The naming task has often been opposed to the lexical decision task as a paradigm that does not involve either postaccess mechanisms or operations of integration occurring at levels higher than the lexical.

A further, and more obvious, test of the proposed explanation is therefore to repeat Experiment 1 using a naming task. Since this task does not entail postaccess checking processes, a priming effect is expected with both synonyms and antonyms.

\section{EXPERIMENT 4}

\footnotetext{
Method

Subjects. Two groups of 14 students from the University of Padua served as subjects in this experiment.

Material. The sentence contexts and the words to be used as targets were the same as in Experiment 1. The only change was made in the lists of targets; the nonword fillers were replaced by words, and mean length of the words was 7.8 letters.

Procedure. The subjects were randomly assigned to two groups of 14 subjects each. One group was assigned to prime-target synonyms, and the other to prime-target antonyms. The procedure was the same as in Experiment 1, except that the subjects had to name the target word aloud, as quickly and as accurately as possible. A voice key was connected to the Apple Ile microcomputer; the timer started measuring reaction times from the appearance of the target
}

word on the monitor display, and stopped when the subject initiated pronouncing the word. At the end of the experiment, the subjects were given a recognition test in which they had to cross out the sentences they recognized. The test comprised a list of sentences, 11 of which were the same as those presented to the subjects auditorily while the others were either similar or completely unrelated to the test sentences.

\section{Results and Discussion}

Reaction times above or below $2 S D$ were replaced by the mean reaction times of the subject over all conditions $(0.6 \%$ of the data was removed in this way). In addition, $0.6 \%$ of the data were removed, either because they exceeded $1,200 \mathrm{msec}$ or because of failure of the equipment. Items that were mispronounced were considered errors. Mean correct reaction times are displayed in Table 2.

Target-naming times were facilitated by both synonym and antonym primes, relative to the control [subjects, $F(1,26)=11.4, p<.01$; items, $F(1,34)=8.19$, $p<.01 ; \min F(1,60)=4.7, p<.05$ ]. The $F$ ratio for the interaction was very low, 0.8 for both subject and item analyses. The only other significant result, found in the analysis by items, was that the type of relation (synonyms vs. antonyms) produced significantly different reaction times $[F(1,34)=18.3, p<.001]$. Errors were infrequent, $2.7 \%$ of the total set of data.

The results of Experiment 4 confirm that when the target word must simply be named, and postaccess processes are excluded or minimized by the nature of the task, the presence of a semantic relationship between the prime and the target facilitates naming of the latter. This result supports the view that in Experiment 1 the presence of a related prime facilitated recognition of the antonym target word, but this effect was cancelled at a postaccess stage by a conflict arising at the level of integration with the sentence context.

Further support for our interpretation can be found in Neely's recently proposed theory of how semantic context influences word recognition (Neely \& Keefe, in press; Neely, Keefe, \& Ross, in press). According to these authors, a retrospective mechanism of semantic matching occurs in the lexical decision task, which can be influenced by both the proportion of related trials and the proportion of nonwords in the experiment. Their analysis of how a retrospective mechanism operates is indeed very consistent with our results. First, they showed that with low-dominance category exemplars, only the seman-tic matching mechanism is responsible for the priming effect. Facilitation effects obtained from the retrospective mechanism are small and inhibition is large, whereas ex-

Table 2

Mean Reaction Times (RT) and Percentage of Errors in the Naming Experiment (Experiment 4)

\begin{tabular}{lccccc}
\hline \multirow{2}{*}{ Type } & \multicolumn{2}{c}{ Related Pairs } & & \multicolumn{2}{c}{ Unrelated Pairs } \\
\cline { 2 - 3 } \cline { 5 - 6 } of Target & RT & \% Errors & & RT & \% Errors \\
\hline Synonyms & 571 & 1.6 & & 590 & 3.9 \\
Antonyms & 619 & 2.4 & & 652 & 3.1 \\
\hline
\end{tabular}


pectancy produced more facilitation. Since low-dominance category targets are similar to the semantically related but nonassociated targets used in the present Experiments 1, 2 , and 4 , the prediction from their theory would be exactly consistent with our data. Namely, a small facilitation effect with semantically related pairs would be cancelled by inhibition produced by the semantic matching strategy detecting an incongruency with the sentence-level representation. On the other hand, the larger effect produced by associates (Experiment 3 ) would reflect the expectancy mechanism and would be attenuated, not cancelled, by the retrospective mechanism. Second, the retrospective mechanism is only active in the lexical decision task, not in the naming task.

It could conceivably be argued that many priming studies have found facilitation even when the context did not bias, or was not in any way congruent with, the prime word. Indeed, cross-modal priming studies of lexical ambiguity (Onifer \& Swinney, 1981; Seidenberg, Tanenhaus, Leiman, \& Bienkowski, 1982; Swinney, 1979) have shown that facilitation of target lexical decisions is obtained even when the targets are completely unrelated to the context biasing the ambiguous prime. In the present study, however, in which the neutral sentence including the prime creates the effective context, the target is not just unrelated to the sentence, but is in fact in opposition with what is claimed by the context, therefore creating an anomalous completion. In other words, it is more difficult to integrate two events that are opposed than two events that are simply unrelated. In previous studies, the target words were very rarely, if ever, in this relation of opposition, either with the overall sentence context or with the prime word itself. An examination of the materials used in these studies shows that the majority of the primes and targets were synonyms, hyponyms, and strong normative associates (see, e.g., the materials published in Onifer \& Swinney, 1981; Tanenhaus \& Donenworth-Nolan, 1984; Tanenhaus, Leiman, \& Seidenberg, 1979; Van Petten \& Kutas, 1987). Given the impact of those studies on the research on priming, further direct experimental support is required. Experiment 5 was a replication of Experiment 1, designed to strengthen and further support the results obtained.

\section{EXPERIMENT 5}

\section{Method}

Subjects. Two groups of 18 subjects were randomly selected to take part in this experiment.

Material and Procedure. The materials and procedure were exactly the same as in Experiment 1, except that at the end of the experiment, the subjects were given the recognition test in exactly the same way as in Experiment 4.

\section{Results and Discussion}

Mean correct reaction times were trimmed as before; responses exceeding $1,200 \mathrm{msec}(1.8 \%)$ were automatically excluded from the analyses, and items above or below $2 S D$ from the mean reaction time (1.4\%) for each subject were cut off. The result of interest, the interac-
Table 3

Mean Reaction Times (RT) and Percentage of Errors in Experiment 5

\begin{tabular}{cccccc}
\hline \multirow{2}{*}{$\begin{array}{c}\text { Type } \\
\text { of Target }\end{array}$} & \multicolumn{2}{c}{ Related Pairs } & & \multicolumn{2}{c}{ Unrelated Pairs } \\
\cline { 2 - 3 } \cline { 5 - 6 } & RT & \% Errors & & RT & \% Errors \\
\hline Synonyms & 693 & 3.7 & & 731 & 4.3 \\
Antonyms & 690 & 1.8 & & 691 & 2.5 \\
\hline
\end{tabular}

tion of the between-subjects factor of type of relationship (synonyms vs. antonyms) and the within-subjects factor of relatedness (related vs. unrelated) was significant in both the subject and item analyses [subjects, $F(1,34)=$ $4.1, p<.05$; items, $F(1,34)=4.3, p<.05$ ] (see Table 3 ). The priming effect for synonyms in the replication experiment was $38 \mathrm{msec}$, significant both by subjects $[F(1,17)=7.1, p<.05]$ and by items $[F(1,17)=$ $9.2, p<.01, \min F(1,33)=4, p>.05]$. The priming effect for antonyms was $1 \mathrm{msec}$, not significant in either analysis [subjects, $F(1,17)=.01$; items, $F(1,17)=.008$ ] The only other significant effect was that of relatedness [subjects, $F(1,34)=4.7, p<.05$; items, $F(1,34)=4.9$, $p<.05]$. There were no significant differences in the error rates. The pattern of results of Experiment 1 was clearly replicated: there was no tendency for facilitation of antonym targets in the lexical decision task.

\section{GENERAL DISCUSSION}

The experiments reported in this paper show that the presence of a semantic relation between two words immediately following each other does not necessarily produce priming of lexical decisions. The nature of the semantic relation is important, at least when considered in interaction with a larger sentence context. A semantic relation of antonymy between two words yielded a facilitation effect when the two words were not in a sentential context (Experiment 2). Within a neutral sentence context, the priming of antonym targets disappeared, although it remained for synonyms. Experiment 4 showed that this was not because recognition of the antonym targets was not primed. We conclude, therefore, that a postrecognition process, operative only in the lexical decision task, obscured the facilitation of recognition itself. This interpretation is supported by the results of Experiment 3, which showed that by increasing the strength of the relationship between the antonym pairs, priming of lexical decisions could be obtained from words in sentences, a result that we have argued is due to the increased facilitation of recognition obtained with these pairs.

The above explanation distinguishes the relationship between prime word and target and between sentence context and target in a way that is similar to the distinction between local and global sources of contextual facilitation in reading proposed by Schustack, Ehrlich, and Rayner (1987). Their experiments compared fixation times upon a word in a normal reading task with the naming time of the same word, and they found that the first task is sensitive both to local variables, such as the semantic relation- 
ship with the preceding verb, and to more global variables, such as coreference with prior mention of the same word. In contrast, the naming task was only sensitive to the semantic restrictiveness of the preceding verb. Similarly, in the present experiments, naming was sensitive to a local relationship with the immediately preceding word, whereas lexical decision was sensitive to the global consistency between the target and sentence meaning. If we assume that both fixation times and lexical decisions are influenced by postrecognition processes, whereas naming reflects only recognition time, then these findings converge on the view that certain types of relationship between a word and its context are only influential once that word has been recognized. Moreover, the present results extend this argument to the processing of words that do not need to be integrated into the sentence, but which form part of a secondary task performed in a different modality. Consequently, it would appear likely that they are best accounted for in terms of an automatic tendency to "make sense" of linguistic information with respect to prior context.

What is suggested is that the coherence between the meaning retrieved from the target and that of the context is important, since the presence of coherence is a reliable and quickly detectable cue to "wordness" (Balota \& Lorch, 1986; de Groot, Thomassen, \& Hudson, 1982). Hence, the meaning retrieved from a word in a sentence might prime its antonym via links at the conceptual level, just as it does when presented in isolation, and this may also facilitate the retrieval of meaning of the target word. However, the difference seems to be that while, for example, the word "damp" is considered to be coherent with the single word "dry," due to semantic similarity, it is considered incoherent with the sentence fragment "In order to be kept dry ..." This is presumably because, in the latter case, the conflict between the two meanings interferes in some way with the development of a coherent sentence representation.

Indirect support for this intepretation is offered by a consideration of the results of an experiment by Balota and Lorch (1986). As in the present study, they also found a dissociation between naming and lexical decision tasks, but this time in a single-word priming experiment. They found that, for example, "white" primed the nonassociated word "coal" in the naming task, through the mediation of the common concept "black," as activation spread from "white" to "black" and from "black" to "coal." However, no effect was obtained in the lexical decision task for reaction times, although there was an effect for accuracy (exactly as in our Experiment 1). Balota and Lorch argued that the failure to find an effect for reaction times with the lexical decision task was due to a postaccess checking process intrinsic to the task, which failed to find a direct relation between the prime and the target, because it "is assumed to be sensitive only to the existence of relatively strong associations" (p. 342). But Lupker (1984) has shown that lexical decisions can be primed for pairs which are category coordinates (e.g., "dog-pig"), but which are not associated. In contrast with Lupker's material, however, Balota and Lorch's "mediated-pairs" words were not conceptually related in any apparent way; for example, although "white" and "coal" may both be related to the common concept "black," they do not share features or properties (compare, for another example, "tree" and "syrup" mediated by "maple"). So the failure to find a relation may not have been due to the lack of an association as such, but to the lack of strong interconnections, and consequently to low semantic similarity, between the concepts relative to the prime and the target. In other words, it is suggested that in Balota and Lorch's experiment, the postrecognition mechanism failed to find a "coherence" between the target and the highest available level of representation in that particular situation-namely, the conceptual level-as the words were only in a loose conceptual relation. Assuming a representation in which the lexical level and the conceptual level are separate systems, one could perhaps even argue that the mediated priming they obtained in the naming task occurred entirely at the lexical level. In light of the present data, in which the contextual background was not formed by a word but by the ongoing sentence representation, our suggestion is that the processes occurring after recognition of a word are highly sensitive to the highest possible level of representation of the context, be it the conceptual representation of an isolated word or a sentence representation.

Hence, the present results can best be interpreted as providing evidence for a postrecognition process that is specifically sensitive to the coherence between a word and the prior context. First, they show that the criteria for coherence are flexible. When the context consists of a single word, then semantic similarity seems to be important. However, when the context consists of a sentence, it is the consistency with the developing sentence representation that defines coherence. Hence, an antonym target can be incoherent with the context, even though it is semantically similar to the prime word. Second, this coherencechecking process appears to be sensitive to the highest available level of description of the context. Even at a point very early in a sentence (e.g., "In order to be happy ..."), it is the developing sentence representation that forms the effective context in which the check operates, and not the meanings of individual words. Third, some tasks, such as lexical decision, are particularly sensitive to the processes occurring immediately after a word is recognized, and are more revealing of its interaction with higher levels of representation. The data of experiments using lexical decision in sentence contexts may therefore reflect to a varying extent operations of integration, rather than exclusively processes inherent in word recognition itself.

\section{REFERENCES}

Auble, P., Franks, J. J. (1983). Sentence comprehension processes Journal of Verbal Learning \& Verbal Behavior, 22, 395-405. 
BAlot A, D. A., \& LoRCH, R. F. (1986). Depth of automatic spreading activation: Mediated priming effects in pronunciation but not in lexical decision. Joumal of Experimental Psychology: Learning, Memory, \& Cognition, 12, 336-345.

BeCKer, C. A. (1980). Semantic context effects in visual word recognition: An analysis of semantic strategies. Memory \& Cognition, 8 , 493-512.

BeCKER, C. A., \& KiLLION, T. H. (1977). Interaction of visual and cognitive effects in word recognition. Journal of Experimental Psychology: Human Perception \& Performance, 3, 389-401.

Bortolini, U., Tagliavini, C., Zampolli, A. (1982). Lessico di frequenza della lingua italiana contemporanea. Milan: Garzanti.

Clark, H. H., \& Clark, E. V. (1977). Psychology and language. New York: Harcourt Brace Jovanovich.

DE Groot, A. M. B., Thomassen, A. J. W. M., \& Hudson, P. T. W. (1982). Associative facilitation of word recognition as measured from a neutral prime. Memory \& Cognition, 10, 358-370.

Forster, K. I. (1976). Accessing the mental lexicon. In R. J. Wales \& E. Walker (Eds.), New approaches to language mechanisms (pp. 257-284). Amsterdam: North Holland.

Forster, K. I. (1981). Priming and the effects of sentence and lexical contexts on naming time: Evidence for autonomous lexical processing. Quarterly Journal of Experimental Psychology, 33A, 465-495.

Foss, D. J., \& Ross, J. R. (1983). Great expectations: Context effects during sentence processing. In G. B. Flores d'Arcais \& $\mathbf{R}$. J. Jarvella (Eds.), The process of language understanding (pp. 169-191). New York: Wiley.

Hoffmann, J. E., \& Macmillan, F. W. (1985). Is semantic priming automatic? In M. I. Posner \& O. S. M. Marin (Eds.), Attention and performance $X I$ (pp. 585-599). Hillsdale, NJ: Erlbaum.

LoRCH, R. F., JR. (1982). Priming and search processes in semantic memory: A test of three models of spreading activation. Journal of Verbal Learning \& Verbal Behavior, 21, 468-492.

LUPKER, S. J. (1984). Semantic priming without association: A second look. Journal of Verbal Learning \& Verbal Behavior, 23, 709-733.

Lyons, J. (1977). Semantics. Cambridge: Cambridge University Press.

MeYer, D. E., \& SChVANENVELDT, R. W. (1971). Facilitation in recognizing pairs of words: Evidence of a dependence between retrieval operations. Journal of Experimental Psychology, 90, 227-234.

MorTon, J. (1969). The interaction of information in word recognition. Psychological Review, 76, 165-178.

NeELY, J. H. (1976). Semantic priming and retrieval from lexical memory: Evidence for facilitatory and inhibitory processes. Memory \& Cognition, 4, 648-654.

NeELY, J. H. (1977). Semantic priming and retrieval from lexical memory: Roles of inhibitionless spreading activation and limited capacity attention. Joumal of Experimental Psychology: General, 106, 226-254.

NeEly, J. H., \& KeEFE, D. E. (in press). Semantic context effects on visual word processing: A hybrid prospective/retrospective processing theory. In G. H. Bower (Ed.), The psychology of learning and motivation: Advances in research and theory (Vol. 23). New York: Academic Press.

Neely, J. H., Keefe, D. E., \& Ross, K. (in press). Semantic priming in the lexical decision task: Roles of prospective prime-generated expectancies and retrospective semantic matching. Joumal of Experimental Psychology: Learning, Memory, \& Cognition.

NorRIs, D. (1986). Word recognition: Context effects without priming. Cognition, 22, 93-136.

ONIFER, W., \& SWINNEY, D. A. (1981). Accessing lexical ambiguities during sentence comprehension: Effects of frequency of meaning and contextual bias. Memory \& Cognition, 9, 225-236.

Parisi, D., \& Pizzamiglio, L. (1967). Dati quantitativi sulle associazioni verbali di studenti italiani. Rome: Bulzoni Editore.

SANFORD, A. J., \& GARROD, S. (1981). Understanding written language. New York: Wiley.

Schustack, M. W., Ehrlich, S. F., \& RaYNer, K. (1987). Local and global sources of contextual facilitation in reading. Journal of Memory \& Language, 26, 322-340.

Seidenberg, M. S., Tanenhaus, M. K., Leiman, J. L., \& BienKowsKI, M. (1982). Automatic access of the meanings of ambiguous words in context: Some limitations of knowledge-based processing. Cognitive Psychology, 14, 489-537.
Seidenberg, M. S., Waters, G. S., Sanders, M., \& Langer, P. (1984). Pre- and postlexical loci of contextual effects on word recognition. Memory \& Cognition, 12, 315-328.

Sмiтн, M. C. (1979). Contextual facilitation in a letter search task depends on how the prime is processed. Journal of Experimental Psychology: Human Perception \& Performance, 5, 239-251.

SWINNEY, D. A. (1979). Lexical access during sentence comprehension: (Re)consideration of context effects. Journal of Verbal Learning \& Verbal Behavior, 18, 645-679.

Tanenhaus, M. K., \& Donenworth-Nolan, S. (1984). Syntactic context and lexical access. Quarterly Journal of Experimental Psychology, 36A, 649-662.

Tanenhaus, M. K., Leiman, J. H., \& Seidenberg, M. S. (1979). Evidence for multiple stages in the processing of ambiguous words in syntactic contexts. Journal of Verbal Learning \& Verbal Behavior, $18,427-440$.

Van Petten, C., \& Kutas, M. (1987). Ambiguous words in context: An event-related potential analysis of the time course of meaning activation. Journal of Language \& Memory, 26, 188-208.

WARREN, R. E. (1974). Association, directionality and stimulus encoding. Journal of Experimental Psychology, 102, 151-158.

WILLIAMS, J. N. (1988). Constraints upon semantic activation during sentence comprehension. Language \& Cognitive Processes, 3, 165-206.

\section{NOTE}

1. The reaction times reported in previous reports of the data of Experiments 1-4 were slightly different, because they did include extreme scores. However, the pattern of data was the same.

\section{APPENDIX}

A. Priming and control sentences used in Experiment 1 and relative target words (synonyms and antonyms), along with their English translations.

1. Dicono che essere calmi (tranquillo, nervoso) non è facile per un mediterraneo.

They say that to be calm (quiet, nervous) isn't easy for a Mediterranean.

Dicono che essere alti (tranquillo, nervoso) non è comune per un cinese.

They say that to be tall (quiet, nervous) isn't common for a Chinaman.

2. A volte il dolore (pena, gioia) anche se non è molto forte, è difficile da sopportare.

Sometimes suffering (pain, joy), even if it is not very deep, is difficult to cope with.

A volte il colore (pena, gioia), anche se non è molto vistoso, è difficile da abbinare.

Sometimes a color (pain, joy), even if it is not very gaudy, is difficult to match.

3. Non è molto appropriato essere comici (buffo, serio), quando si fa politica.

It is not very appropriate to be comical (funny, serious) when one is a politician.

È molto appropriato essere curati (buffo, serio), quando si fa politica.

It is very appropriate to be smart (funny, serious) when one is a politician.

4. Troppo spesso solo perché uno è veloce (svelto, lento) non à detto che sia efficiente.

Too often just because someone is quick (swift, slow), they are not necessarily efficient. 
Troppo spesso solo perché uno è profondo (svelto, lento) non è detto che sia originale.

Too often just because someone is profound (swift, slow), they are not necessarily original.

5. Per essere stata tenuta al secco (arido, umido) la pianta perse tutte le foglie.

Because it had been kept dry (arid, humid), the plant lost all of its leaves.

Per essere stata tenuta al chiaro (arido, umido) la pianta rifioriva rigogliosa.

Because it had been kept in the light (arid, humid), the plant flowered luxuriantly.

6. Sfortunatamente proprio quando fu sulla cima (vetta, base) si accorse di non poter più vedere il sentiero che l'aveva condotto sulla montagna.

Unfortunately, just when he was at the peak (summit, bottom), he realized that he could no longer see the path that had brought him up the mountain.

Sfortunatamente proprio quando fu nella cava (vetta, base) si accorse di aver dimenticato il prezioso strumento di misurazione.

Unfortunately, just when he was in the cave (summit, bottom), he realized that he had forgotten the precious measuring instrument.

7. Per essere allegro (felice, triste) il signore ha dovuto bere più del solito.

In order to be jolly (happy, sad), the man had to drink more than usual.

Per essere gentile (felice, triste) il signore ha invitato i suoi amici ad una festa.

In order to be kind (happy, sad), the man invited his friends to a party.

8. Se uno è cupo (tetro, gaio) rende la vita miserevole agli altri.

If someone is gloomy (dreary, gay), they make life miserable for others.

Se uno è ricco (tetro, gaio) rende la vita più comoda alla sua famiglia.

If someone is rich (dreary, gay), they make life more comfortable for their family.

9. Sfortunatamente dopo la salita (ascesa, discesa), che era troppo ripida, l'autobus si fermò, perciò i passeggeri dovettero spingerlo.

Unfortunately, after the hill (ascent, descent), which was too steep, the bus stalled, and the passengers had to push it.

Sfortunatamente dopo la vacanza (ascesa, discesa), che era troppo costosa, il ragazzo rimase senza soldi.

Unfortunately, after the holiday (ascent, descent), which was too expensive, the boy was left with no money.

10. Sul giomale era scritto che se uno è malato (infermo, sano) può avere un'assistenza adeguata solo se ha molti soldi.

In the newspaper it was written that if someone is ill (sick, healthy), they can receive adequate care only if they have a lot of money.
Sul giornale era scritto che se uno è severo (infermo, sano) può aspettarsi che i figli si ribellino durante l'adolescenza.

In the newspaper it was written that if someone is strict (sick, healthy), they can expect that their children will be rebellious during adolescence.

11. Per diventare più agile (lesto, goffo) la ragazza ha deciso di cominciare a fare ginnastica.

In order to become more agile (swift, clumsy), the girl decided to start a gymnastics course.

Per diventare più bellina (lesto, goffo) la ragazza ha deciso di cominciare un corso di trucco.

In order to become more pretty (swift, clumsy), the girl decided to start a makeup class.

12. Poiché aveva un po' di paura (timore, coraggio) il ragazzo non voleva imparare a guidare.

Because he was a bit afraid (timid, courageous), the boy did not want to learn to drive.

Poiché aveva un po' di febbre (timore, coraggio) il ragazzo non poteva giocare a pallone.

Because he was a bit feverish (timid, courageous), the boy was not able to play ball.

13. C'era sempre troppo rumore (chiasso, silenzio), troppa gente e troppa ansia a casa e quindi la ragazza non poteva studiare.

There was always too much noise (din, silence), too many people, and too much tension at home, and so the girl was not able to study.

C'era sempre troppa ansia (chiasso, silenzio), troppa gente e troppo numore a casa e quindi la ragazza non poteva studiare.

There was always too much tension (din, silence), too many people, and too much noise at home, and so the girl was not able to study.

14. Alla televisione hanno detto che era sicuro (certo, incerto), se il cambio fosse caduto, che l'economia sarebbe migliorata.

On television they said that it was sure (certain, uncertain), that if the exchange rate fell, the economy would improve.

Alla televisione hanno detto che era meglio (certo, incerto), se il cambio fosse caduto, che il governo prendesse qualche decisione.

On television they said that it was better (certain, uncertain) that if the exchange rate fell, the government took a decision.

15. Essere famoso (noto, ignoto) non è l'ambizione di tutti.

To be well known (famous, unknown) is not everyone's ambition.

- Essere docile (noto, ignoto) non è sempre conveniente a tutti. To be meek (famous, unknown) is not always convenient for everyone.

16. Poiché era debole (gracile, robusto), quell'uomo non poteva sollevare troppi pesi.

Because he was weak (frail, robust), the man couldn't lift heavy weights.

Poiché era ingenuo (gracile, robusto), quell'uomo era sempre ingannato. 
Because he was naive (frail, robust), the man was always deceived.

17. Dato che era fine (sottile, grosso) il cavo si è fuso quando è stata fatta partire la lavatrice.

Given that it was fine (thin, thick), the cable shorted when the washing machine was switched on.

Dato che era rotto (sottile, grosso) il cavo non poteva essere usato.

Given that it was broken (thin, thick), the cable could not be used.

18. Per essere breve (corto, lungo) il professore ha escluso molti fatti importanti dalla sua conferenza.

In order to be brief (short, long), the professor excluded many important facts from his talk.

Per essere lodato (corto, lungo) il professore ha impiegato molto tempo per preparare la sua conferenza.

In order to be praised (short, long), the professor spent a long time preparing his talk.

B. Priming and control sentences used in Experiment 3 (associated antonyms).

1. Dicono che essere alti (basso) non è facile per un cinese. They say that to be tall (short) isn't easy for a Chinaman.

Dicono che essere calmi (basso) non è facile per un mediterraneo.

They say that to be calm (short) isn't easy for a Mediterranean.

2. Per essere più bella (brutto) la ragazza ha deciso di cominciare un corso di trucco.

In order to be more beautiful (ugly), the girl decided to start a makeup course.

Per essere più snella (brutto) la ragazza ha deciso di cominciare un corso di ginnastica.

In order to be more fit (ugly), the girl decided to start a gymnastics course.

3. Era diventato così bianco (nero) dopo la notizia, che sembrava stesse per svenire.

He had become so white (black) after the news that he looked as if he was about to faint.

Era diventato così debole (nero) dopo la malattia, che non poteva reggersi in piedi.

He had become so weak (black) after the illness that he was not able to stand up.

4. Quando è troppo corto (lungo) un abito può rendere una donna poco elegante.

When it is too short (long), a dress can make a woman seem inelegant.

Quando è troppo ricco (lungo) un uomo può diventare arrogante.

When he is too rich (long), a man can become arrogant.

5. Per essere stata tenuta al chiaro (scuro) la pianta rifioriva rigogliosa.

Because it had been kept in the light (dark), the plant flowered luxuriantly.
Per essere stata tenuta al secco (scuro) la pianta perse tutte le foglie.

Because it had been kept dry (dark), the plant lost all its leaves.

6. Essendo stato così freddo (caldo) l'uomo non si aspettava di essere accolto in modo molto caloroso.

Being so cold (hot), the man didn't expect a very warm reception.

Essendo stato così tirchio (caldo) l'uomo non si aspettava di ricevere tanti regali.

Being so stingy (hot), the man didn't expect to receive many gifts.

7. Quando un oggetto appare vicino (lontano) sembra più grande.

When an object appears near (far) it seems larger.

Quando un oggetto appare rigido (lontano) sembra molto più resistente.

When an object appears stiff (far) it seems much more resistant.

8. A pochi piace qualcosa di amaro (dolce) mentre a molti piace qualcosa di zuccherato.

Few people like something bitter (sweet), while many like something sweet.

A pochi piace qualcosa di serio (dolce) mentre a molti piace ridere e divertirsi.

Few people like something serious (sweet), while many like to laugh and enjoy themselves.

9. Quando uno è giovane (vecchio), talvolta si comporta in modo irresponsabile.

When someone is young (old), sometimes they behave irresponsibly.

Quando uno è sciocco (vecchio), talvolta si comporta in modo irresponsabile.

When someone is stupid (old), sometimes they behave irresponsibly.

10. Come era stato previsto, siccome era molto largo (stretto) lo specchio non passava dalla porta.

As predicted, since it was very wide (narrow), the mirror would not pass through the door.

Come era stato previsto, siccome era molto lucido (stretto) lo specchio faceva molti riflessi nella stanza.

As predicted, since it was very shiny (narrow), the mirror produced lots of reflections in the room.

11. Di solito è facile (difficile), specialmente se si frequenta un corso, imparare una lingua quando si è nel paese nel quale la si parla.

Usually it is easy (difficult), especially if you attend a course, to learn a language when you are in the country in which it is spoken.

Di solito è costoso (difficile), specialmente se si frequenta un corso, imparare una lingua quando si è nel paese nel quale la si parla.

Usually it is expensive (difficult), especially if you attend a course, to learn a language when you are in the country in which it is spoken. 
12. Essendo diventata così magra (grasso) la donna aveva perso tutta la sua bellezza.

Having become so skinny (fat), the woman had lost all of her beauty.

Essendo diventata così pallida (grasso) la donna aveva perso tutta la sua bellezza.

Having become so pale (fat), the woman had lost all of her beauty.

13. Poiché voleva diventare più grande (piccolo) il ragazzo si vestiva come un uomo.

Because he wanted to become more big (small), the boy dressed himself up like a man.

Poiché voleva diventare elegante (piccolo) il ragazzo si vestiva come un uomo.
Because he wanted to become more elegant (small), the boy dressed himself up like a man

14. Se uno tiene molto alla propria vita (morte) cerca di guidare con prudenza

If someone values their own life (death), they try to drive carefully

Se uno tiene molto alla propria casa (morte) cerca di arredarla con cura.

If someone values their own home (death), they try to furnish it with care.

(Manuscript received September 7, 1988; revision accepted for publication May 10, 1989.) 